\title{
Role of atmospheric heating over the South China Sea and western Pacific regions in modulating Asian summer climate under the global warming background
}

\author{
Bian $\mathrm{He}^{1} \cdot$ Song Yang ${ }^{2,3} \cdot$ Zhenning $\mathrm{Li}^{2}$
}

Received: 2 January 2015 / Accepted: 29 June 2015 / Published online: 11 July 2015

(C) The Author(s) 2015. This article is published with open access at Springerlink.com

\begin{abstract}
The response of monsoon precipitation to global warming, which is one of the most significant climate change signals at the earth's surface, exhibits very distinct regional features, especially over the South China Sea (SCS) and adjacent regions in boreal summer. To understand the possible atmospheric dynamics in these specific regions under the global warming background, changes in atmospheric heating and their possible influences on Asian summer climate are investigated by both observational diagnosis and numerical simulations. Results indicate that heating in the middle troposphere has intensified in the SCS and western Pacific regions in boreal summer, accompanied by increased precipitation, cloud cover, and lowertropospheric convergence and decreased sea level pressure. Sensitivity experiments show that middle and upper tropospheric heating causes an east-west feedback pattern between SCS and western Pacific and continental South Asia, which strengthens the South Asian High in the upper troposphere and moist convergence in the lower troposphere, consequently forcing a descending motion and adiabatic warming over continental South Asia. When air-sea interaction is considered, the simulation results are overall more similar to observations, and in particular the bias of
\end{abstract}

Song Yang

yangsong3@mail.sysu.edu.cn

1 State Key Laboratory of Numerical Modeling for Atmospheric Sciences and Geophysical Fluid Dynamics, Institute of Atmospheric Physics, Chinese Academy of Sciences, Beijing 100029, China

2 Department of Atmospheric Sciences, Sun Yat-sen University, 135 West Xingang Road, Guangzhou 510275, Guangdong, China

3 Institute of Earth Climate and Environment System, Sun Yat-sen University, Guangzhou, China precipitation over the Indian Ocean simulated by AGCMs has been reduced. The result highlights the important role of air-sea interaction in understanding the changes in Asian climate.

Keywords Global warming - Atmospheric heating · Climate feedback $\cdot$ Asian summer monsoon

\section{Introduction}

Global warming is a significant climate phenomenon in the late twentieth century. The Fifth Assessment Report (AR5) of the Intergovernmental Panel on Climate Change (IPCC 2013) systematically analyzed the combined land and sea surface temperature (SST) over the globe based on three kinds of data sets (Hansen et al. 2010; Morice et al. 2012; Vose et al. 2012), and concluded that the global-mean trends were significant in each case. The warming was about $0.85^{\circ} \mathrm{C}\left(0.65-1.06{ }^{\circ} \mathrm{C}\right)$ from 1880 to 2012 and about $0.72{ }^{\circ} \mathrm{C}\left(0.49-0.89{ }^{\circ} \mathrm{C}\right)$ from 1951 to 2012 , with the $2000 \mathrm{~s}$ being the warmest decade. Moreover, the spatial distribution of warming showed a maximum mainly over the midhigh latitude land of the Northern Hemisphere.

Different from the continuous rise of surface temperature, the change in global monsoon precipitation is quite complicate. Observational analyses (e.g. Wang and Ding 2006; Zhang and Zhou 2011) show an overall weakening trend in the past 60 years, with a clear reduction of summer monsoon rainfall in the Northern Hemisphere. However, monsoon precipitation exhibits very distinct spatial features in response to global warming. Smith et al. (2012) reconstructed the global monthly precipitation anomalies since 1900s and showed that there were dry trends over the South Asian land mass and the northwestern Pacific Ocean, 
but wet trends over the South Asian oceans and near the equatorial Pacific Ocean in boreal summer. The dry trend over continental South Asia is robust during 1949-2000, while the precipitation changes in adjacent oceans are quite uncertain (Annamalai et al. 2013).

The change in precipitation over the Asian monsoon region has attracted much interest not only because the monsoon affects a large proportion of the world's population, but also because it involves very complicated air-sealand interaction processes. Zhou et al. (2009) reviewed the recent progress in understanding the variability of Asian summer monsoon and concluded that the topical ocean warming (Hoerling and Kumar 2003; Barlow et al. 2007; Annamalai et al. 2013), the forcing of the Tibetan Plateau (Duan and Wu 2005; Wu et al. 2012; Liu et al. 2012) and aerosol (Collier and Zhang 2009; Wang et al. 2009; Lau and Kim 2010; He et al. 2013), and atmospheric internal variability (Ding et al. 2007a, b) are all key processes that modulate the activity of monsoon over East Asian land, the South China Sea (SCS), and the surrounding oceans. Many previous studies have emphasized on the response of precipitation to external forcing, but the internal feedback by precipitation on monsoon circulation has seldom been discussed.

The role of atmospheric heating in modulating largescale atmospheric dynamics is undoubtedly an important issue to address (Matsuno 1966). Webster (1972) proposed that most of the time-independent circulation over low latitudes is forced by heating and orography within the tropics and the subtropics. Further studies (e.g. Gill 1980) show that the tropical east-west asymmetry circulation can be illustrated by solutions for heating concentrated in specific areas. Yang and Webster (1990) found that the summer tropical heating was very important for determining the location and magnitude of westerly jet streams over the other hemisphere. Rodwell and Hoskins (2001) revealed that the equatorward portion of each subtropical anticyclone might be viewed as a Kelvin wave response to monsoon heating over the continent to the west. Recently, Wu et al. (2015) argued that the formation of upper troposphere temperature maximum over the Asian continent in boreal summer could not be attributed to the local convection over Indian flatland, but to the increasing latent heating over East Asia.

Despite these studies, the dynamics of climate changes over the SCS and the Indian and western Pacific Oceans under global warming background remains unclear. For example, Annamalai et al. (2013) suggested the robust rise of SST over the warm pool, anchored by an increase in greenhouse gas (GHG) concentration, is instrumental for the east-west shift of monsoon rainfall, i.e. enhanced rainfall over the tropical western Pacific and decreased rainfall over South Asia. However, although the SST has increased even more significantly in the Indian Ocean than in the western Pacific under global warming, precipitation has decreased over the Indian Ocean.

Therefore, in this study, we seek answers for two specific questions: (1) What are the characteristics of the change in atmospheric heating over the SCS, western Pacific, and Indian Ocean regions under the background of global warming? (2) How does the changed heating influence Asian climate? We first diagnose the characteristics of the change in atmospheric heating over the SCS and adjacent regions in observations, and then use both atmospheric general circulation model (AGCM) and coupled general circulation model (CGCM) to identify the influence of the changed atmospheric heating on Asian summer climate.

The remainder of the paper is structured as follows. Section 2 introduces data sets and model configuration. Section 3 diagnoses the changes in heating over the SCS and surrounding regions based on observations and reanalysis data sets. Section 4 presents experimental design and results from numerical experiments, especially those about the influence of atmospheric heating over the SCS and western Pacific on Asia summer climate and the associated mechanisms. Finally, a discussion and a summary of the key findings are provided in Sect. 5.

\section{Data sets and model configuration}

\subsection{Data sets}

Two data sets of monthly mean global surface temperature are used in this study. One is the Hadley Centre sea ice and sea surface temperature (HadISST) data set (Rayner et al. 2003), which includes SST with a grid resolution of $1^{\circ} \times 1^{\circ}$, and it is available at http://www.metoffice.gov.uk/ hadobs/hadisst/data/download.html. The other is the Goddard Institute for Space Studies (GISS) Surface Temperature Analysis data set (Hansen et al. 2010), which combines both land and SSTs. This data set is on a $2^{\circ} \times 2^{\circ}$ grid and covers the period from 1880 to present with monthly mean anomalies. It is available at http://data.giss.nasa.gov/gistemp/. The precipitation data used is the National Oceanic and Atmospheric Administration (NOAA) Precipitation Reconstruction (PREC) data set (Chen et al. 2002), which is an analysis of monthly precipitation constructed on a $2.5^{\circ} \times 2.5^{\circ}$ grid over the globe for the period from 1948 to present. This data set is available at http://www.esrl.noaa.gov/psd/ data/gridded/data.prec.html. The International Comprehensive Ocean-Atmosphere Data Set (ICOADS) is also used for analyzing sea level pressure and clouds. The data set is on a $2^{\circ} \times 2^{\circ}$ grid and spans from 1800 to present (Woodruff et al. 2011), and it is available at http://icoads.noaa. gov/. Also used is the National Centers for Environmental 
Prediction (NCEP) Reanalysis (Kalnay et al. 1996), which includes multi-level air temperature, specific humidity, and winds with a $2.5^{\circ} \times 2.5^{\circ}$ grid resolution. This data set, covering the period from 1948 to present, is available at http:// www.esrl.noaa.gov/psd/data/gridded/data.ncep.reanalysis.html. Finally, the European Centre for Medium-range Weather Forecasts (ECMWF) ERA40 Reanalysis (Uppala et al. 2005) is used. The data set includes a $1.125^{\circ} \times 1.125^{\circ}$ grid resolution and covers the period from 1958 to 2001 . It is available at http://apps.ecmwf.int/datasets/.

\subsection{Model configuration}

The Flexible Global Ocean-Atmosphere-Land System Model spectral version 2 (FGOALS-s2) is the main climate system model used in this study. It is composed of four individual components: version 2 of the Spectral Atmosphere Model (SAMIL2) developed at the State Key Laboratory of Numerical Modeling for Atmospheric Sciences and Geophysical Fluid Dynamics, Institute of Atmospheric Physics (LASG/IAP) (Wu et al. 1996; Bao et al. 2010); version 2 of the LASG/IAP Climate System Ocean Model (LICOM2) (Liu et al. 2013); version 3 of the Community Land Model (CLM3) (Oleson et al. 2004); and version 5 of the Community Sea Ice Model (CSIM5) (Briegleb et al. 2004). The exchanged fluxes among these components are connected by the coupler module 6 of the National Center for Atmospheric Research (Collins et al. 2006). The basic performance of these models is described in Bao et al. (2013).

The atmospheric model, SAMIL2, has an R42 horizontal resolution $\left(2.81^{\circ}\right.$ in longitude and $1.66^{\circ}$ in latitude) with 26 vertical layers in a $\sigma-p$ hybrid coordinate, extending from the surface to $2.19 \mathrm{hPa}$. The mass flux cumulus parameterization of Tiedtke (1989) is used to calculate convective precipitation. The cloud scheme is a diagnostic method (Slingo 1987; Kiehl et al. 1996), and a low-cloud statistical method (Dai et al. 2004) is also applied. A nonlocal scheme is employed to calculate the eddy-diffusivity profile and turbulent velocity scale, and the model incorporates nonlocal transport effects for heat and moisture (Holtslag and Boville 1993). The employed radiation scheme is an updated Edwards-Slingo scheme (Edwards and Slingo 1996; Sun and Rikus 1999).

\section{Observational analysis}

To obtain a specific and qualitative concept of the warming background over the SCS and adjacent ocean regions in summer during the late twentieth century, we first examine the evolution of both global and regional JJA SSTs from 1880 to 2012 based on the HadISST and GISS data sets

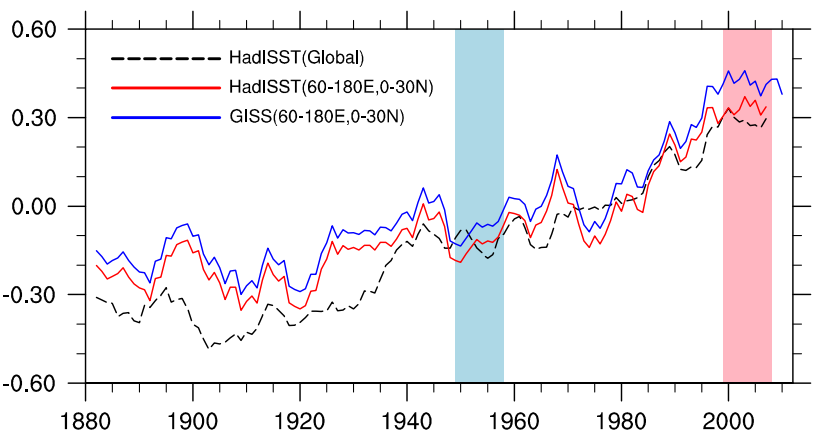

Fig. 1 Time series of JJA mean SST $\left({ }^{\circ} \mathrm{C}\right)$ anomalies (relative to 1961-1990) with a 5-year running mean of HadISST (dashed black line global mean values; solid red line regional mean values in $60^{\circ}-180^{\circ} \mathrm{E} / 0^{\circ}-30^{\circ} \mathrm{N}$ for the SCS and surrounding ocean regions), and GISS (blue line regional mean values in $60^{\circ}-180^{\circ} \mathrm{E} / 0^{\circ}-30^{\circ} \mathrm{N}$ ). The light blue shading indicates the period from 1949 to 1958, and the light red shading indicates the period from 1999 to 2008

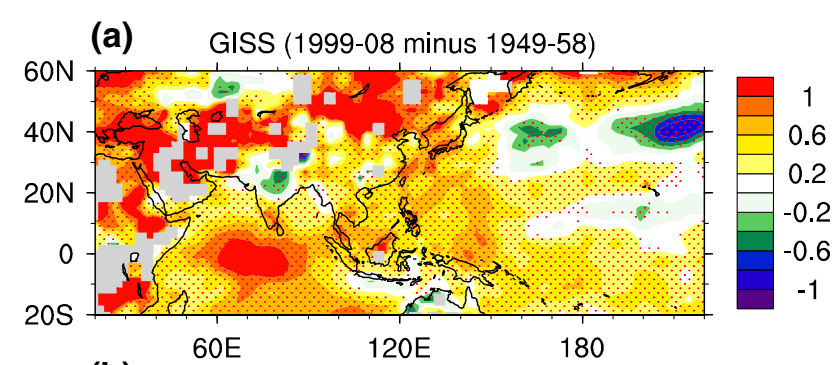

(b) HadISST (1999-08 minus 1949-58)

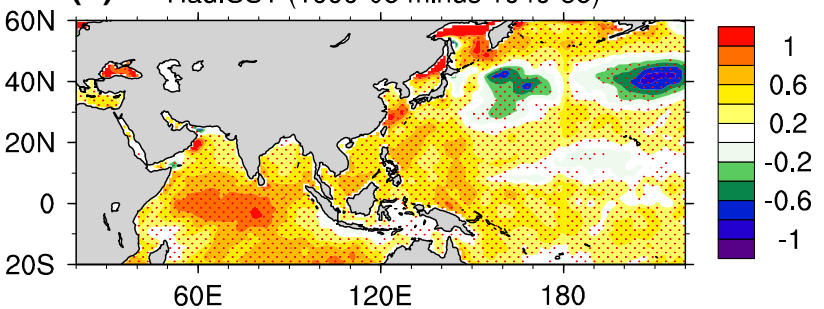

(c) PREC (1999-08 minus 1949-58)

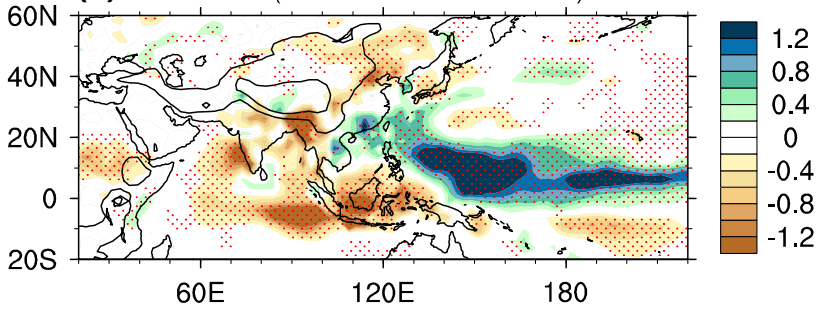

Fig. 2 Difference in JJA mean surface temperature $\left({ }^{\circ} \mathrm{C}\right)$ between high global warming state (1999-2008 mean) and low global warming state (1949-1958 mean) for a GISS and b SST from HadISST. c As in a but for precipitation $\left(\mathrm{mm} \mathrm{day}^{-1}\right)$ in PREC. The black contours in c denote 1000- and 3000-m topography heights, respectively. The red dotted areas denote regions where the changes are statistically significant at the $95 \%$ confidence level according to the Student's $t$ test 
(Fig. 1). It is clearly shown that global warming is significant (black dashed line), with a linear trend of $0.77{ }^{\circ} \mathrm{C}$ in 133 years, which is compatible with the annual mean surface temperature given by the IPCC AR5. Furthermore, the evolution of mean $\mathrm{SST}$ over $60^{\circ}-180^{\circ} \mathrm{E} / 0^{\circ}-30^{\circ} \mathrm{N}$ shows similar variations to the global values in both HadISST (black solid line) and GISS (blue line). The corresponding linear trends are 0.59 and $0.62{ }^{\circ} \mathrm{C}$, respectively, which are slightly lower than the global mean values. Thus, the analysis of multiple data sets confirms that the warming trend over the SCS and adjacent ocean regions is robust.

Given that GHGs have increased rapidly after the 1950s and the rise of surface temperature from 1950s to present contributes about $85 \%$ of the total warming from the $1850 \mathrm{~s}$ to the current time (IPCC 2013), we define two climate mean states to distinguish the climate backgrounds between low and high global warming states. The climate mean of 1949-1958 is regarded as a low global warming climate state (light blue shading in Fig. 1), and the climate mean of 1999-2008 is regarded as a high global warming climate state (light red shading in Fig. 1) (we choose 1958-1967 as the low warming state and 1992-2001 as the high warming state for ERA40 because of its shorter data record). Their difference represents the total climate response to the global warming effect. Based on this definition, the spatial differences in GISS surface temperature, HadISST SST, and PREC precipitation between the two states are computed and shown in Fig. 2. The change in observed surface temperature (Fig. 2a) indicates that the most significant warming over land covers central and northeastern Asia. The most significant warming over oceans occurs in the tropical Indian Ocean $\left(>1{ }^{\circ} \mathrm{C}\right)$, while the warming in the SCS and western Pacific regions is about $0.4-0.8{ }^{\circ} \mathrm{C}$. The HadISST (Fig. 2b) shows a similar warming pattern over oceans as in the GISS, but the warming in tropical oceans is a little weaker. Different from the relatively uniform warming in SST, the change in JJA precipitation under global warming shows distinct regional features (Fig. 2c). Precipitation increases over the SCS, the western Pacific Ocean, and South China, and decreases over the BOB, the India subcontinent especially the southern slope of the Tibetan Plateau (TP) (black contours denote the 1000 and $3000 \mathrm{~m}$ topography heights), the Arabian Sea, the tropical Indian Ocean, and North China. The changes in precipitation over land are relatively reliable since the data sets are produced from station measurements, whereas those over oceans are more uncertain because the data are reconstructed using an EOF analysis method (Chen et al. 2002). Because direct long-term observations of precipitation over the SCS and the western Pacific are unavailable, the long-term changes of sea level pressure (SLP) and clouds over oceans under global warming are further analyzed using the ICOADS data sets in the next paragraph.

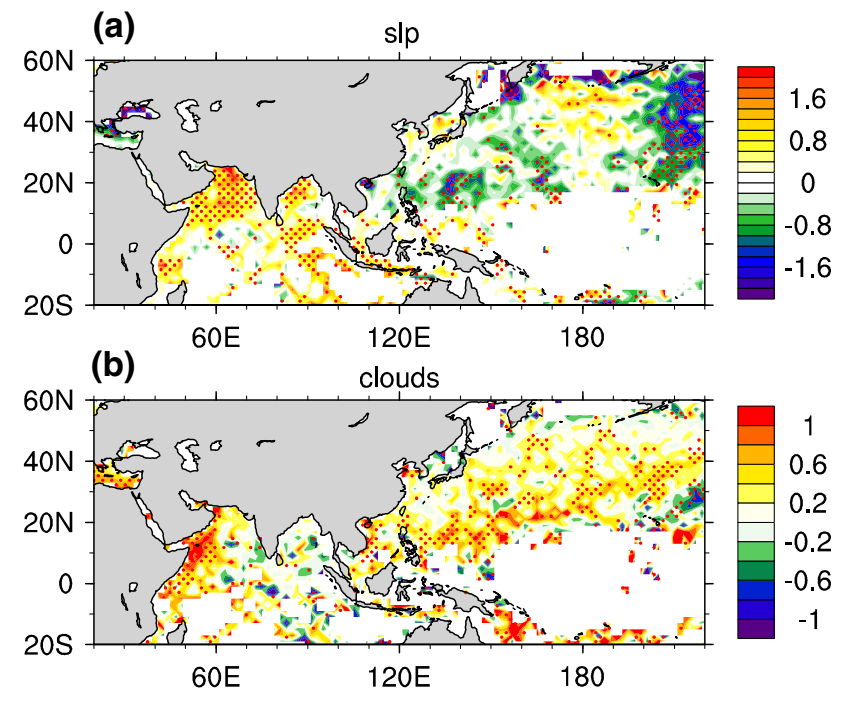

Fig. 3 a Difference in JJA mean SLP (hPa) between high global warming state (1999-2008 mean) and low global warming state (1949-1958 mean) for ICOADS. b As in a but for observed cloud cover (okta) in ICOADS. The red dotted areas denote regions where the changes are statistically significant at the $95 \%$ confidence level according to the Student's $t$ test. The white areas denote missing data values

Figure $3 \mathrm{a}$ shows the difference in JJA mean SLP between the two climate states. SLP drops in most of the SCS and western Pacific regions, but increases across nearly the entire Indian Ocean. Decreased SLP, mainly covering $110^{\circ}-180^{\circ} \mathrm{E} / 10^{\circ}-30^{\circ} \mathrm{N}$ (the data set contains missing values to the south of $10^{\circ} \mathrm{N}$ in the Pacific as denoted by the white-filled color), implies that convergence and ascending motion may intensify over the SCS and the western Pacific regions, while increased SLP implies that divergence and descending motion may dominate over the Indian Ocean under the background of global warming. The spatial pattern of changes in SLP is overall consistent with that in precipitation (Fig. 2c) over the SCS, the western Pacific, and the central-eastern Indian Ocean. As shown in Fig. 3b, increased cloud cover is apparent over the SCS and the western Pacific, while a clear decrease in cloud cover appears over the BOB and the tropical Indian Ocean except the east coast of Africa and the Arabian Peninsula. Therefore, the combined analysis of the differences in the east-west patterns of changes in clouds, SLP, and precipitation suggests that the occurrence of moist convection has increased over the SCS and western Pacific regions but decreased over the Indian Ocean. This feature resembles the result from regression analysis for 1949-2000 by Annamalai et al. (2013).

Based on the above analysis, we specifically estimate the change in heating over the SCS and western Pacific regions between the high and low global warming climate states. We calculate the change in apparent heating $Q_{1}$ as 

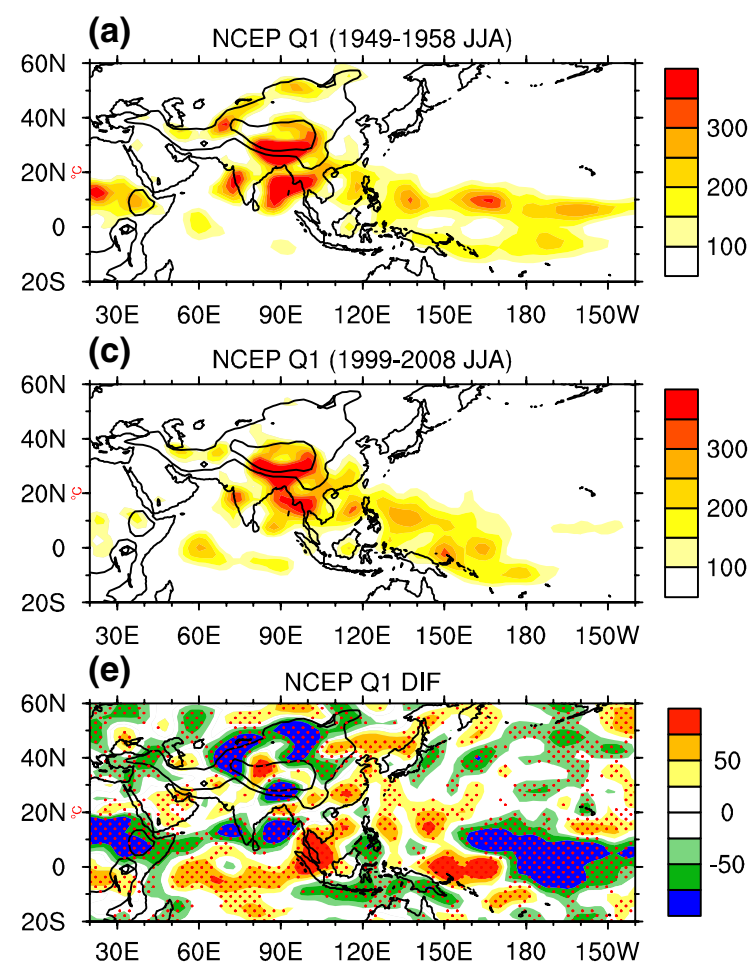

Fig. 4 Column integrated diabatic heating $\left(\mathrm{W} \mathrm{m}^{-2}\right)$ for JJA means of low global warming state in a NCEP/NCAR Reanalysis (1949-1958 mean) and b ERA40 Reanalysis (1958-1967 mean). c As in a but for high global warming state (1999-2008 mean). d As in b but for high global warming state (1992-2001 mean). e Difference between the two climate states (c minus a) for NCEP/NCAR Reanalysis. f Dif-

defined by Yanai et al. (1973) from both the NCEP/NCAR Reanalysis (Fig. 4a) and the ERA40 Reanalysis (Fig. 4b). The $Q_{1}$ consists of heating due to radiation, release of latent heat by net condensation, and vertical convergence of the vertical eddy transport of sensible heat. We also compare the climatological $Q_{1}$ in the NCEP/NCAR and ERA40 reanalyses with the total diabatic heating estimated by the direct calculation of radiative heat, latent heat, and the vertical transport of sensible heat in the NCEP Climate Forecast System Reanalysis (CFSR) for 1979-2008 (figure not shown). It is found that $Q_{1}$ is largely contributed by the latent heating term especially in the free troposphere, while contributions by the other kinds of heating are small. Thus, to some extent the change in $Q_{1}$ between the two climate states can be regarded mainly as the change in latent heat. Figure 4a shows the climatological JJA mean $Q_{1}$ from 1949 to 1958 , from the NCEP/NCAR Reanalysis. Two maxima of $Q_{1}$ are found in the SCS and northern New Guinea. In the high global warming state (climatological mean of 1999-2008), both centers expand to the surrounding oceans (Fig. 4c). The difference in $Q_{1}$ between 1999 2008 and 1949-1958 shows that $Q_{1}$ increases significantly over the SCS and western Pacific regions but decreases over the south of the Tibetan Plateau, the BOB, and the
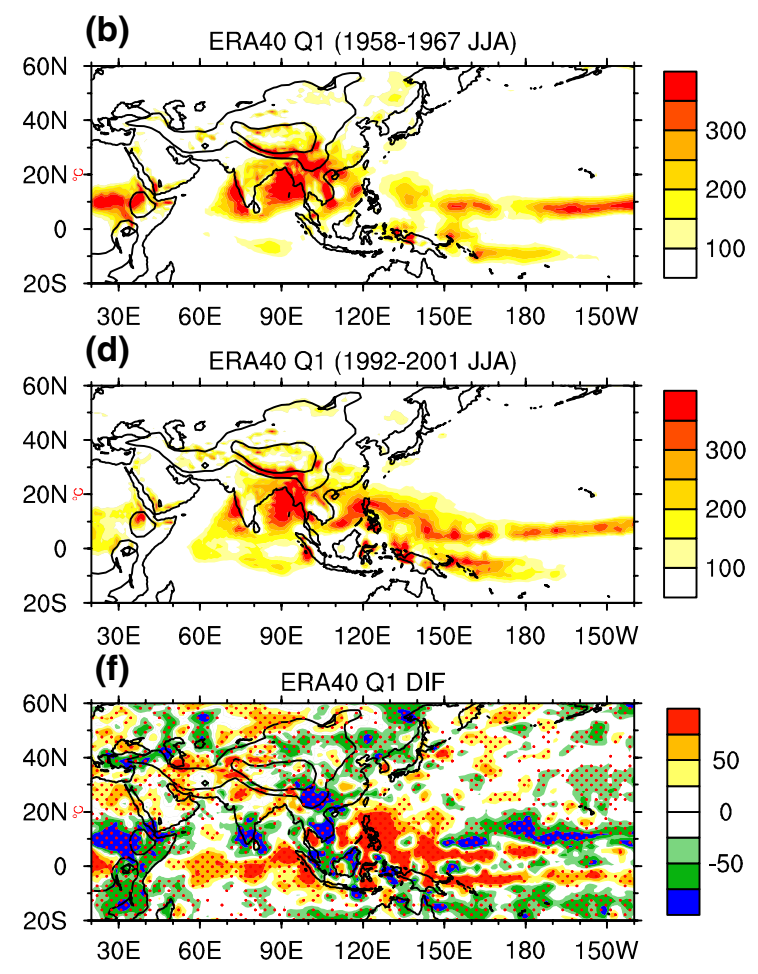

ference between the two climate states ( $\mathbf{d}$ minus b) for ERA40. The black contours denote 1000- and 3000-m topography heights, respectively. The red dotted areas denote regions where the changes are statistically significant at the $95 \%$ confidence level according to the Student's $t$ test

Arabian Sea (Fig. 4c). The ERA40 exhibits similar $Q_{1}$ patterns for both the low (Fig. 4a, b) and the high (Fig. 4c, d) global warming states, confirming that the basic $Q_{1}$ patterns presented are robust. It should be noted that the $Q_{1}$ difference in ERA40 (Fig. 4f) shows a clearer increase in heating over the SCS and western Pacific regions, which is closer to the observed precipitation pattern shown in Fig. 2c. Consequently, we use ERA40 as the primary reanalysis in the following analysis.

The changes in $Q_{1}$ must be accompanied by differences in atmospheric circulations. Therefore, we calculate the changes in JJA mean velocity potential and divergent winds at $850 \mathrm{hPa}$ (Fig. 5a) and $200 \mathrm{hPa}$ (Fig. 5b). A convergence center exists in the lower troposphere over the SCS (Fig. 5a), while a divergence center appears in the upper troposphere over the Philippines (Fig. 5b). Furthermore, the changes in 500-hPa vertical velocity (Fig. 5c) show a strong ascending motion over the SCS and western Pacific regions. The air thickness in the troposphere (200-850 hPa) also presents an obvious increase, with a maximum over the SCS and the western Pacific (Fig. 5d), implying an increase in latent heating. All of these atmospheric changes support our conclusion that moist convection processes and corresponding latent heat release have intensified over the 

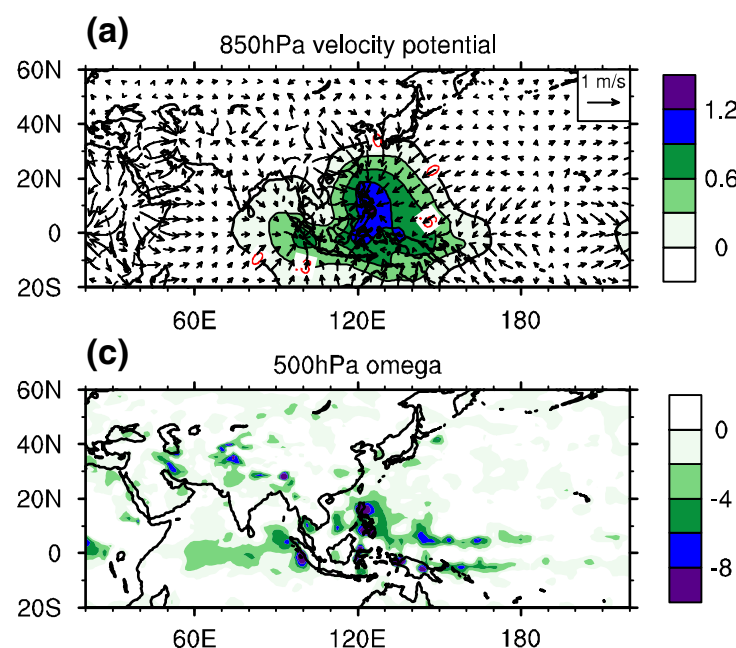

Fig. 5 a Difference in 850-hPa JJA mean velocity potential (contour, $10^{-6} \mathrm{~m}^{2} \mathrm{~s}^{-1}$ ) and divergent winds (vector, $\mathrm{m} \mathrm{s}^{-1}$ ) between high global warming state and low global warming state from ERA40 Reanalysis. The shaded regions denote convergence areas. b As in a but for the $200-\mathrm{hPa}$ velocity potential and divergent winds, and the

Table 1 Model experimental design

\begin{tabular}{ll}
\hline Name & Description \\
\hline CON & $\begin{array}{c}\text { AGCM run, the climatology SST from } 1949 \text { to } 1958 \text { is } \\
\text { used as low boundary, and other external forcings are } \\
\text { prescribed as their } 1949 \text { values. The model is integrated } \\
\text { for } 30 \text { years }\end{array}$ \\
CON_CP $\quad$ CGCM run, the external forcings are the same as in \\
CON but SST is simulated. The model is integrated for \\
50 years \\
AGCM run, the climatology SST from 1999 to 2008 is \\
used as low boundary, and other external forcings are \\
prescribed as their 1999 values. The model is integrated \\
for 30 years \\
AGCM run, same SST and other external forcings \\
as in CON, but a specific heating profile in region \\
HEAT \\
$110^{\circ}-150^{\circ}$ E/ $0^{\circ}-30^{\circ}$ N is added during June-July- \\
August (JJA). The heating is derived from the monthly \\
mean output from SEN minus CON in the same region. \\
The model is integrated for 30 years
\end{tabular}

SCS and western Pacific regions between the two climate states.

Therefore, by systematically analyzing the changes in SST, precipitation, SLP, clouds, atmospheric diabatic heating, and atmospheric circulations between the high and low global warming states, we reveal that the convection processes and heating in the middle troposphere over the SCS and western Pacific regions have increased, while the heating over the southern slope of the TP, the BOB, and the Arabian Sea has decreased. Thus, the first question

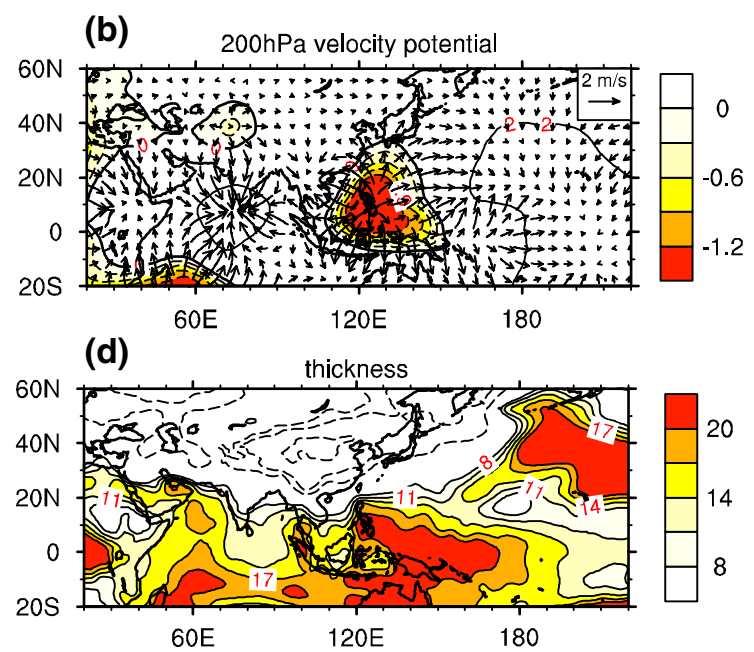

shaded regions denote divergence areas. $\mathbf{c}$ As in a but for the $500-\mathrm{hPa}$ vertical velocity (shaded, $\mathrm{hPa} \mathrm{s}{ }^{-1}$ ), and the shaded regions denote ascending areas. $\mathbf{d}$ As in a but for the thickness (contour, $\mathrm{m}$ ) between 200 and $850 \mathrm{hPa}$. The regions where air column becomes thicker are shaded

posed in the beginning of the paper has been answered. It is known that atmospheric heating is an important forcing on atmospheric circulations. To understand the influence of increased atmospheric heating over the SCS and western Pacific regions on Asian climate and the associated physical processes, i.e. to answer the second question posed in this study, we carry out a series of numerical experiments and analyze the results in the following section.

\section{Numerical simulations}

\subsection{Experimental design}

To investigate the influences of heating over SCS and western Pacific on Asian summer climate, we conduct five experiments, whose designs are shown in Table 1. Two types of control runs are carried out using an AGCM and a CGCM, respectively. The first, referred to as CON, is performed by SAMIL2 with the climatological mean SST from 1949 to 1958 and other external forcings such as $\mathrm{CO}_{2}$, ozone, and aerosol set to their values in 1949. Model integration is 30 years and the mean values of the last 20 years are analyzed. The second, referred to as CON_CP, is performed by FGOALS-s2. The model setup is the same as CON except that the SST is simulated. The model is integrated for 50 years and, the mean values of the last 20 years are analyzed after SST reaches a quasi-equilibrium state.

Three sensitivity runs are then performed to identify the atmospheric responses to global warming and the influences of heating over the SCS and surrounding regions. 
The first, referred to as SEN, is performed by SAMIL2 with the climatological mean SST from 1999 to 2008 and other external forcings set to their values in 1999. The model takes 30-year integration and the mean values of the last 20 years are analyzed. The difference between SEN and CON denotes the atmospheric response to global warming in the late twentieth century, and the result excludes the biases from SST simulation. To distinguish the effect of heating over the SCS and western Pacific regions from other forcings, a sensitivity experiment called HEAT is performed using SAMIL2, in which SST and other external forcings are set to exactly the same as in $\mathrm{CON}$ but heating is added to the region of $110^{\circ}-150^{\circ} \mathrm{E} / 0^{\circ}-30^{\circ} \mathrm{N}$ (where heating increases most significantly) during June-July-August (JJA). The specific heating is derived from the monthly mean output from SEN minus CON in the same region. In addition, a coupled experiment named HEAT_CP is performed based on FGOALS-s2 to investigate the role of air-sea interaction induced by the heating over the SCS and western Pacific regions. All settings of HEAT_CP are exactly the same as in CON_CP, but the same heating as in HEAT is added. As for FGOALS-s2, the model is integrated for 50 years and the results of the last 20 years are analyzed.

\subsection{Model evaluation}

Before analyzing the influence of heating over the SCS and western Pacific regions, we first assess model performance in capturing the response of precipitation to global warming. Figure 6a shows the difference in JJA mean precipitation between SEN (experiment forced by prescribed SST and GHGs in high global warming state) and CON (experiment forced by prescribed SST and GHGs in low global warming state). Precipitation increases significantly over the SCS and western Pacific regions and decreases over the southern slope of the TP and the Arabian Sea. This spatial pattern is consistent with observation (Fig. 2c), except that the positive anomaly over the central Indian Ocean (Fig. 6a) is relatively larger than the observed (Fig. 2c). The difference in total heating (SEN-CON; Fig. 6b) exhibits a spatial pattern similar to the change in precipitation (Fig. 6a), which implies that the change in total heating is largely contributed by the latent heating in the free troposphere. Heating increases significantly over the SCS and the western Pacific, consistent with the results of ERA40 (Fig. 4f), although the magnitude is larger. To understand the effect of increased heating, we derive the heating profile from SEN minus CON, both of which are forced by observed SST, as the heating added to sensitivity experiments. The domain where heating is added is $110^{\circ}-150^{\circ} \mathrm{E} / 0^{\circ}-30^{\circ} \mathrm{N}$ since maximum heating is mainly from the SCS to the east of the Philippines. The JJA-mean vertical diabatic heating (a)

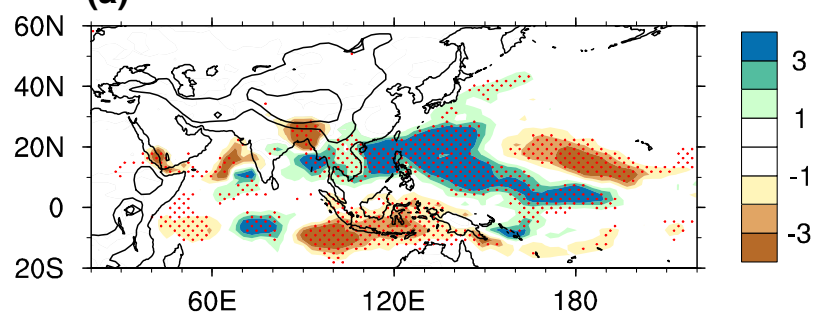

(b)

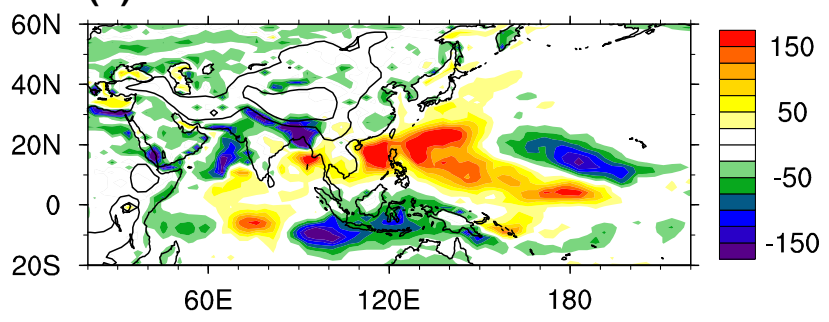

(c)

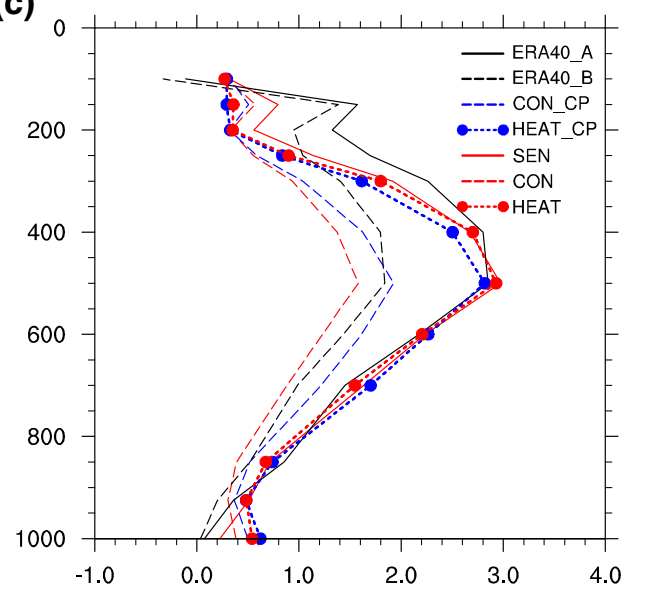

Fig. 6 a Difference in JJA precipitation $\left(\mathrm{mm} \mathrm{day}^{-1}\right)$ between CON and SEN. The red dotted areas denote regions where the changes are statistically significant at the $95 \%$ confidence level according to the Student's $t$ test. The black contours denote 1000- and 3000-m topography heights, respectively. b Difference in total column latent heating $\left(\mathrm{W} \mathrm{m}^{-2}\right.$ ) between SEN and CON. c Total diabatic heating profile $\left(\mathrm{K} \mathrm{day}^{-1}\right)$ for region $0^{\circ}-30^{\circ} \mathrm{N} / 110^{\circ}-150^{\circ} \mathrm{E}$ in each experiment

profiles in various experiments are shown in Fig. 6c (for $\left.110^{\circ}-150^{\circ} \mathrm{E} / 0^{\circ}-30^{\circ} \mathrm{N}\right)$. Total diabatic heating reaches its maximum at $400-500 \mathrm{hPa}$ in all the experiments and the ERA40 Reanalysis. The total diabatic heating profiles of CON, CON_CP, and ERA40_B (1958-1967 mean in ERA40), which stand for the low global warming state, are close to each other, with maxima all lower than $2 \mathrm{~K}_{\text {day }}{ }^{-1}$. Furthermore, the heating profile of SEN (solid red line) is close to $3 \mathrm{~K} \mathrm{day}^{-1}$ in the middle troposphere, which is also similar to the profile of ERA40_A. Furthermore, the heating profiles of HEAT (red line) and HEAT_CP (blue line) are both close to the profile of SEN, indicating that our sensitivity experiments successfully capture the heating characteristics over the SCS and the western Pacific while keeping other external forcings unchanged. These results 
lend confidence to our next analysis of the influence of increased heating over the SCS and western Pacific regions on Asia climate.

\subsection{Influence of heating over SCS and western Pacific on summer monsoons}

The HEAT and HEAT_CP experiments keep all forcings as those in the low global warming state while adding extra heating over the SCS and western Pacific regions during JJA. The specific heating is derived by SEN minus CON, denoting the change in JJA heating under the global warming background. Thus, the results of HEAT minus CON denote the atmospheric response to the change in atmospheric heating over the SCS and the western Pacific, while HEAT_CP minus CON_CP additionally emphasizes the role of air-sea interaction.

The responses of summer monsoon precipitation and 850-hPa winds in AGCM and CGCM are shown in Fig. 7a, $\mathrm{b}$, respectively. It is not surprising that the JJA mean precipitation over the SCS and western Pacific regions, where heating is added, increases significantly. However, it is interesting to see that precipitation decreases over the southern slope of the TP, consistent with the feature observed over continental South Asia (Fig. 2c). Precipitation also decreases significantly over the tropical Indian Ocean, south of the Arabian Peninsula, the eastern equatorial Pacific, and the Bahamas. On the other hand, precipitation increases over the northern Indian Ocean, which is inconsistent with the feature observed (Fig. 2c). At $850 \mathrm{hPa}$, an anomalous cyclonic circulation appears over the SCS and western Pacific regions, and cross-equatorial flow intensifies over the tropical Indian Ocean. All these responses are caused by the heating forcing added over the SCS and western Pacific regions. When air-sea interaction is considered (Fig. 7b), the magnitude of increased precipitation over the SCS and the western Pacific decreases, and the positive precipitation anomaly over the $\mathrm{BOB}$ weakens substantially as well. Meanwhile, the robust response of 850-hPa easterly anomaly near the equatorial Pacific in the AGCM run (Fig. 7a) vanishes in the coupled experiment. Importantly, compared to the result from AGCM (Fig. 7a), the precipitation pattern in the CGCM run (Fig. 7b) is closer to the observed (Fig. 2c), suggesting that air-sea interaction plays an important role in regulating the Asian summer monsoon.

The 200-hPa geopotential height increases significantly over the Asia-Pacific region (Fig. 8a) in the AGCM experiment. The largest semi-permanent circulation system over the Asian continent, the South Asian High (SAH), also expands accordingly. For example, the 12,480-gpm contour is located over central continental Asia in CON (dashed line) but extends westward to Africa and eastward to the

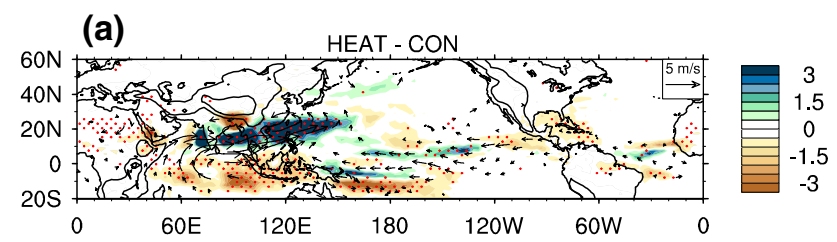

(b)

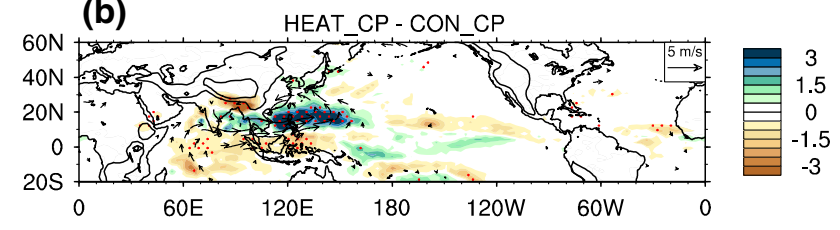

Fig. 7 a Difference in JJA precipitation (shaded, $\mathrm{mm} \mathrm{day}^{-1}$ ) and 850-hPa winds (vector, $\mathrm{m} \mathrm{s}^{-1}$ ) between HEAT and CON. The black contours denote 1000- and 3000-m topography heights, respectively. The red dotted areas denote regions where the changes are statistically significant at the $95 \%$ confidence level according to the Student's $t$ test. b As in a but for the difference between HEAT_CP and CON_CP

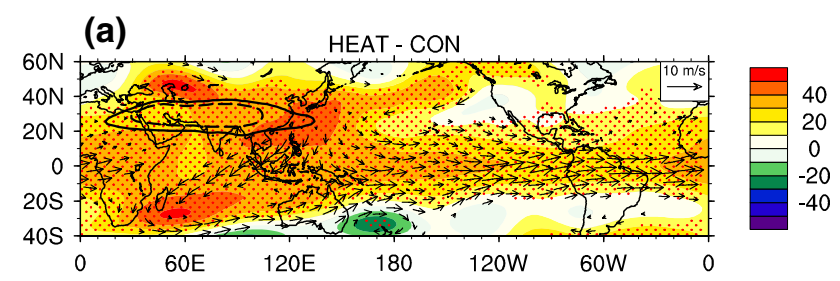

(b)

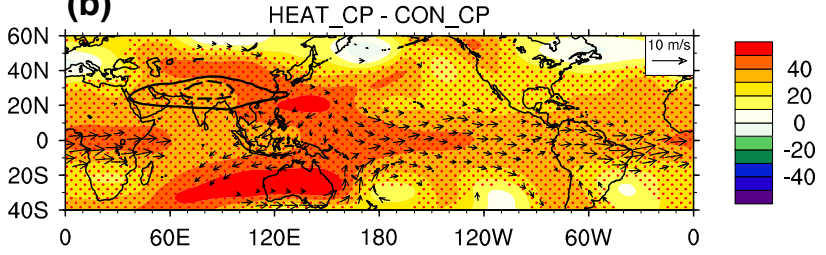

Fig. 8 a Differences in JJA 200-hPa geopotential height (shaded, gpm) and 200-hPa winds (vector, $\mathrm{m} \mathrm{s}^{-1}$ ) between HEAT and CON. The red dotted areas denote regions where the changes are statistically significant at the $95 \%$ confidence level according to the Student's $t$ test. The thick dashed black contour denotes the 12,480 gpm in CON and the thick solid black contour denotes the 12,480 gpm in HEAT. b As in a but for the differences between HEAT_CP and CON_CP. The thick dashed black contour denotes the 12,480 gpm in CON_CP and the thick solid black contour denotes the 12,480 gpm in HEAT_CP

western Pacific in the HEAT run (solid line). On the southeastern edge of the SAH, heating triggers westerly anomalies, which spread out along the equator. The upper-tropospheric response in the CGCM (Fig. 8b) is very similar to the response in the AGCM (Fig. 8a), except that both the $\mathrm{SAH}$ and the equatorial westerly flow are weaker. Given the responses at both upper and lower troposphere, we conclude that the increased JJA heating over the SCS and western Pacific regions reduces the precipitation over continental South Asia and strengthens the SAH through triggering changes in atmospheric circulation. These signals 

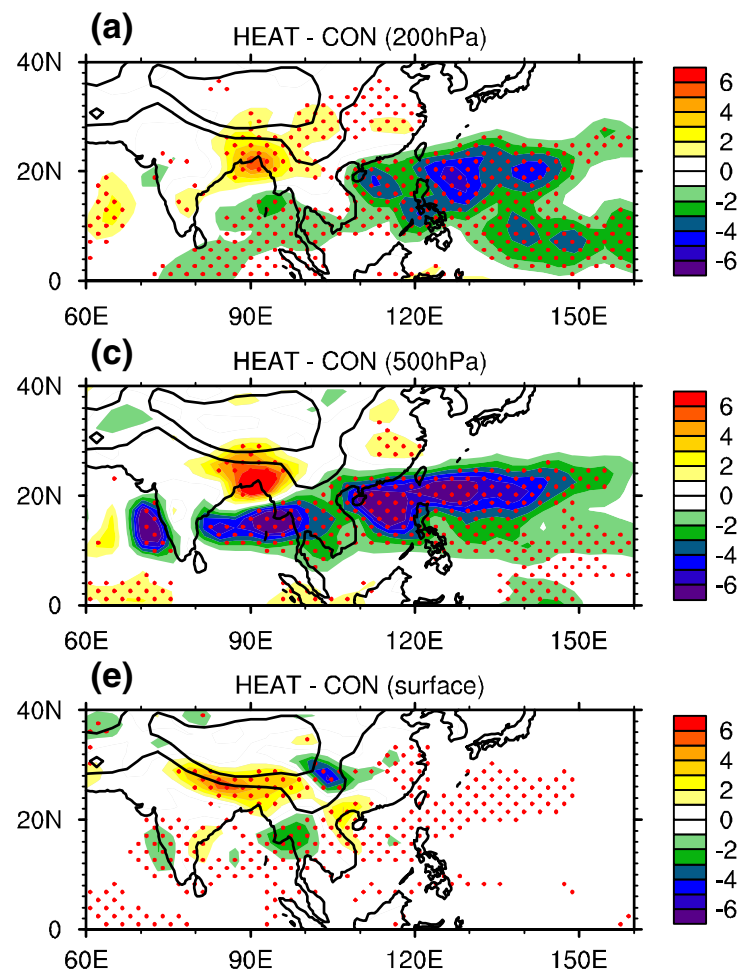

Fig. 9 a Difference in JJA 200-hPa vertical velocity $\left(\mathrm{hPa} \mathrm{s} \mathrm{s}^{-1}\right)$ between HEAT and CON. The negative (positive) values indicate ascending (descending) motions. The red dotted areas denote regions where the changes are statistically significant at the $95 \%$ confidence level according to the Student's $t$ test. The black contours denote

are robust in both AGCM and CGCM sensitivity experiments. Furthermore, the decrease in precipitation over continental South Asia is highly consistent with observation. This finding enriches our understanding about the cause of the recent drying trend in South Asia, which has been attributed previously to the effects of anthropogenic aerosols (Lau and Kim 2010) and rising SST over the western Pacific warm pool (Annamalai et al. 2013).

The physical process involved in the decrease in monsoon precipitation over continental South Asia can be further understood by an atmospheric dynamic analysis. As previous studies (Matsuno 1966; Gill 1980) have revealed, an increase in diabatic heating forces a local ascending motion based on the thermodynamic constrain and the intensity of vertical velocity is proportional to the magnitude of diabatic heating. Similarly in the current study, the response of vertical velocity in the upper and lower troposphere is proportional to the heating that is added. For example, at the surface, the changes in vertical velocity are weak in both AGCM (Fig. 9e) and CGCM (Fig. 9f) experiments, because the heating added at the surface is very small (Fig. 6c). However, maximum ascending motion appears at $500 \mathrm{hPa}$, where maximum heating is added in both AGCM (Fig. 9c) and CGCM (Fig. 9d) runs.

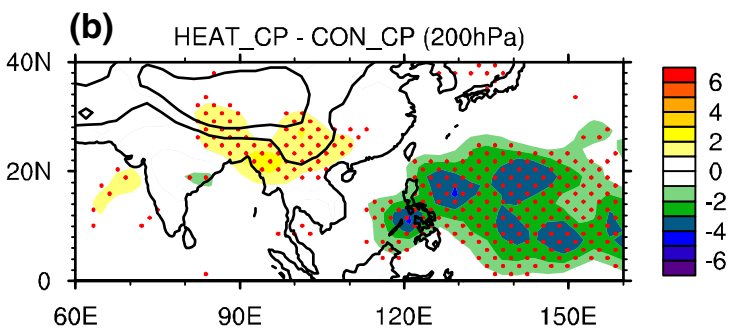

(d) HEAT_CP - CON_CP $(500 \mathrm{hPa})$

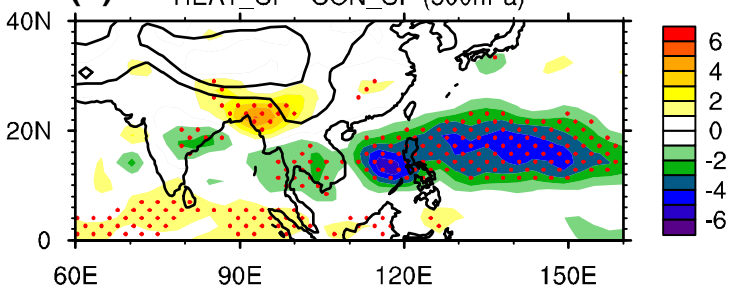

(f) HEAT_CP - CON_CP (surface)

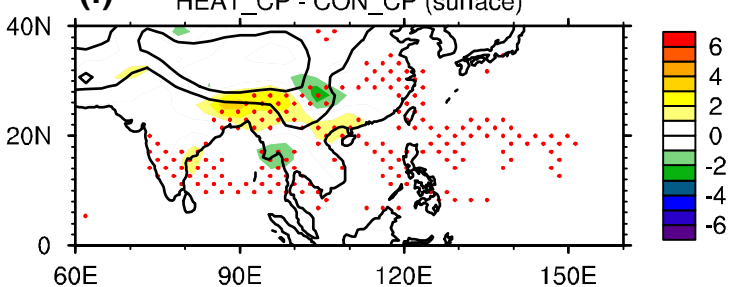

1000- and 3000-m topography heights, respectively. b As in a but for the difference between HEAT_CP and CON_CP. c As in a but for the difference at $500 \mathrm{hPa}$. d As in $\mathbf{b}$ but for the difference at $500 \mathrm{hPa}$. e As in $\mathbf{a}$ but for the difference at the surface. $\mathbf{f}$ As in $\mathbf{b}$ but for the difference at the surface

The ascending motion extends to the upper troposphere (Fig. 9a, b). It is interesting to note that adiabatic descending motions are forced throughout the upper (Fig. 9a, b), middle (Fig. 9c, d), and lower (Fig. 9e, f) troposphere over the South Asian land mass especially near the southern slope of TP and the features are dynamically consistent with the intensified SAH (Fig. 8), which can be regarded as an atmospheric response to the vertically inhomogeneous diabatic heating (Liu et al. 2001; Wu and Liu 2003).

In the regions where upward vertical gradient of diabatic heating is positive, southerly wind will be triggered, leading to a cyclonic convergence (Liu et al. 2001). Figure 10a, b show the changes in lower-tropospheric water vapor fluxes and total column water vapor content for the HEAT minus CON case (Fig. 10a) and the HEAT_CP minus CON_CP case (Fig. 10b). A robust response of water vapor convergence appears over the SCS and western Pacific regions, where the increase in total water vapor content reaches a maximum. The convergence of water vapor is instrumental for increasing precipitation over the SCS and the western Pacific. Meanwhile, the anomalous cyclonic circulation leads to northeasterly wind over continental South Asia and thus less water vapor is transported to India. The adiabatic descending motion in the free troposphere and the 


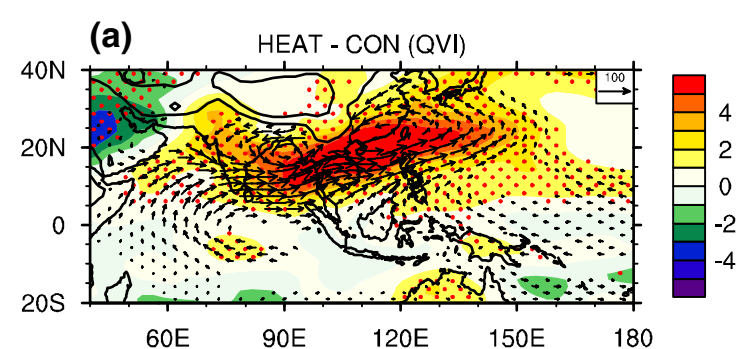

(c)

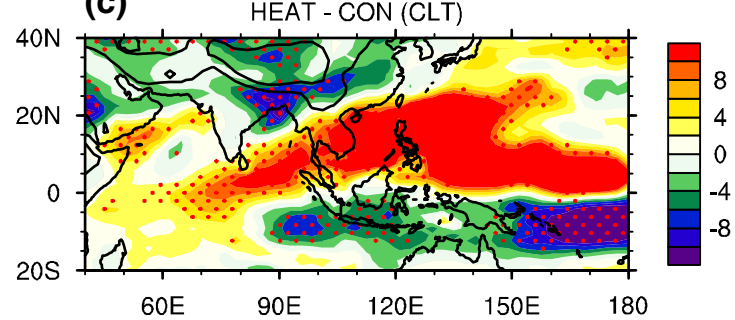

(e)

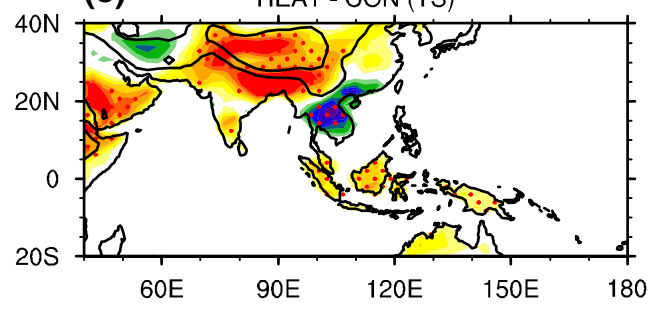

Fig. 10 a Difference in JJA total column water vapor content (shaded, $\mathrm{kg} \mathrm{m}^{-2}$ ) and $850-\mathrm{hPa}$ water vapor fluxes (vectors, $\mathrm{kg} \mathrm{m}^{-1} \mathrm{~s}^{-1}$ ) between HEAT and the CON. The red dotted areas denote regions where the changes are statistically significant at the $95 \%$ confidence level according to the Student's $t$ test. The black contours denote 1000- and 3000-m topography heights, respectively.

near-surface northeasterly wind give a less-cloudy condition (Fig. 10c, d), less rainfall (Fig. 7), and a warmer climate in South Asia especially the southern slope of TP (Fig. 10e, f). The responses in the CGCM are highly consistent with those in the AGCM in the free troposphere, but SST decreases in the SCS and increases in the tropical Indian Ocean (Fig. 10f) in the CGCM runs. The change in SCS SST is consistent with the change in precipitation (Fig. 7b), since an increase in precipitation cools the sea surface.

The observed drying trend in South Asia during the recent decades has attracted much research interest, and several mechanisms for the feature have been proposed with considerations of the effects of increased aerosols (Lau and Kim 2010), SST (Annamalai et al. 2013), and lower troposphere moisture (Chou and Neelin 2004; Held and Soden 2006). Here, we propose that the increase in latent heating over the SCS and western Pacific regions is also an important driving force in regulating the Asian summer climate. The warming and drying summer climate in South Asia shows a closely inherent relationship with the latent heating in the free troposphere over the regions as part of an integrated climate feedback system. The vertically inhomogeneous increased latent (b)

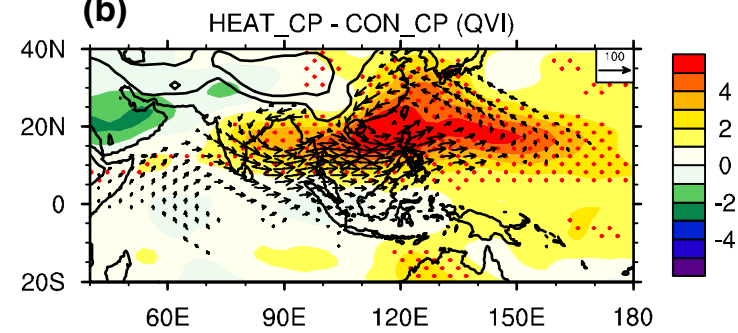

(d)

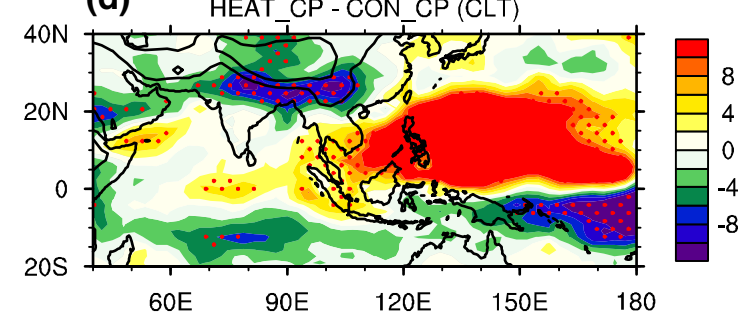

(f) HEAT_CP - CON_CP (TS)

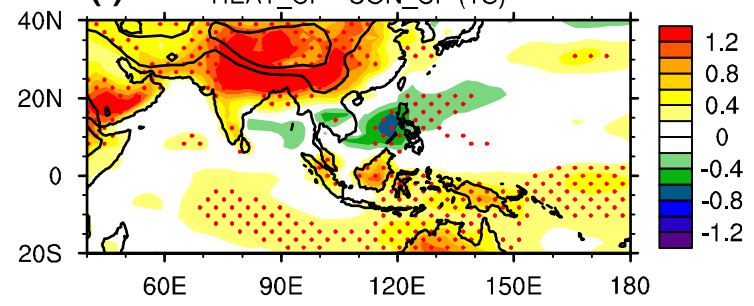

b As in a but for the difference between HEAT_CP and CON_CP. c Difference in JJA total cloud cover (\%) between HEAT and CON. d As in $\mathbf{c}$ but for the difference between HEAT_CP and CON_CP. e Difference in JJA surface temperature $\left({ }^{\circ} \mathrm{C}\right)$ between HEAT and CON. f As in e but for the difference between HEAT_CP and CON_CP

heating in the upper troposphere over the SCS and western Pacific regions strengthens the SAH over continental South Asia, and thus the air column stretches and adiabatic warming appears over the TP, exerting a drying effect over the South Asian land mass. In the lower troposphere, a cyclonic circulation is triggered by the heating added, and thus more water vapor is transported from the Indian Ocean to the east and thus precipitation increases over the SCS and western Pacific regions. These processes lead to an east-west precipitation anomaly pattern between the SCS and western Pacific regions and continental South Asia.

\section{Further discussion and conclusions}

To show the robustness of the results obtained, we apply the NCAR Community Earth System Model (CESM) (Hurrell et al. 2013) in which the Community Atmospheric Model version 4 (CAM4) atmospheric component model is used to repeat all the experiments by the FGOALS-s2. The differences in summer monsoon precipitation and $850-\mathrm{hPa}$ winds between HEAT and CON performed by CAM4 are 


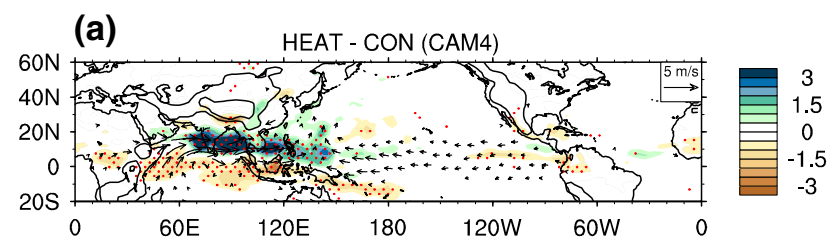

(b)

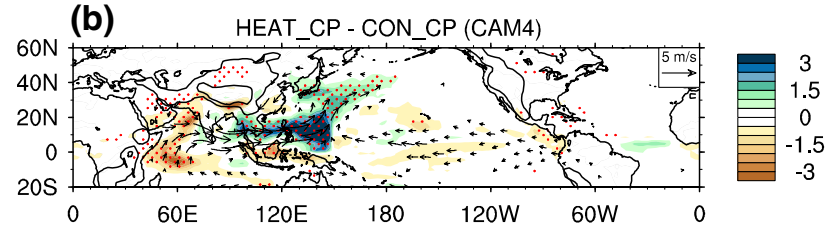

Fig. 11 a Difference in JJA precipitation (shaded, $\mathrm{mm} \mathrm{day}^{-1}$ ) and 850-hPa winds (vector, $\mathrm{m} \mathrm{s}^{-1}$ ) between HEAT and CON performed by CESM with CAM4 atmospheric component model. The red dotted areas denote regions where the changes are statistically significant at the $95 \%$ confidence level according to the Student's $t$ test. The black contours denote 1000- and 3000-m topography heights, respectively. b As in a but for the difference between HEAT_CP and CON_CP

shown in Fig. 11a, while the results with air-sea interaction considered are shown in Fig. 11b. The responses of precipitation and low-level winds are highly consistent with the results from FGOALS-s2 as presented in Fig. 7a, b, except an easterly anomaly over the eastern equatorial Pacific in CESM (Fig. 11b) but not in FGOALS-s2 (Fig. 7b). The similar responses forced by different models confirm our conclusion that an increase in the atmospheric heating over the SCS and western Pacific regions generated from the global warming background drives the dry climate in the western Indian Ocean and continental south Asia.

Furthermore, the increased precipitation to the east (the SCS and western Pacific Ocean regions) and the decreased precipitation in the west (the Arabian Sea) simulated by atmospheric models become more clearly in the air-sea coupled runs, with a significant low-level convergence over the SCS and western Pacific regions, by both FGOALS-s2 and CESM. These results of CGCMs highlight the influence of atmospheric diabatic heating on SST. Increase in SST has long been regarded as an important forcing in triggering convection over oceans and often taken as a boundary condition for AGCMs in simulating atmospheric circulation in various backgrounds including global warming. However, comparing the monsoon responses in both AGCM and CGCM with observations indicates that the precipitation response in CGCM is more similar to observation compared to AGCM, suggesting that the effect of air-sea interaction should be involved in studying the Asian summer monsoon to reduce the bias generated by the prescribed SST in AGCM.

Overall, the major results of this study can be concluded as follows. The observed changes in JJA SST in the SCS and adjacent regions between high and low global warming states include a significant increase in SSTs in the Indian Ocean, the SCS, and the western Pacific, with a maximum in the tropical Indian Ocean. However, the changes in precipitation exhibit a distinct east-west spatial pattern, with increased precipitation over the SCS and western Pacific regions and decreased precipitation over continental South Asia and the tropical Indian Ocean. The changes observed in SLP, clouds, and atmospheric circulations all support an intensification of convection over the SCS and western Pacific regions and an increase in related latent heating in the free troposphere. A series of sensitivity experiments with both AGCM and CGCM indicate that the increased heating in the free troposphere over the SCS and western Pacific regions strengthens the upper-tropospheric South Asian High and forms a lower-tropospheric cyclonic circulation below the heating center. These atmospheric responses force an adiabatic descending motion in continental South Asia and a moist convergence in the SCS and western Pacific regions. The features discussed above demonstrate a positive feedback that intensifies the dry and warm climate in continental South Asia and a moist convective climate in the SCS and western Pacific regions.

Acknowledgments We would like to thank the two anonymous reviewers for their constructive suggestions, which have improved the overall quality of the manuscript. This study was jointly funded by the National Key Basic Research Program of China (Grant 2014CB953904), the National Natural Science Foundation of China (Grants 41405091, 91337110, and 41375081), and the Strategic Leading Science Projects of the Chinese Academy of Sciences (Grant XDA11010402). It was also partially supported by the Guangdong Province Funds for China National "Thousand-Talent Plan" (No. YCJ2013-196) and the Jiangsu Collaborative Innovation Center for Climate Change. Computing resource for model CESM was provided by the high-performance grid computing platform of Sun Yat-sen University and the National Supercomputer Centre in Guangzhou.

Open Access This article is distributed under the terms of the Creative Commons Attribution 4.0 International License (http://creativecommons.org/licenses/by/4.0/), which permits unrestricted use, distribution, and reproduction in any medium, provided you give appropriate credit to the original author(s) and the source, provide a link to the Creative Commons license, and indicate if changes were made.

\section{References}

Annamalai H, Hafner J, Sooraj KP, Pillai P (2013) Global warming shifts the monsoon circulation, drying South Asia. J Clim 26:2701-2718

Bao Q, Wu GX, Liu YM, Yang J, Wang ZZ, Zhou TJ (2010) An introduction to the coupled model FGOALS1.1-s and its performance in East Asia. Adv Atmos Sci 27:1131-1142

Bao Q et al (2013) The flexible global Ocean-Atmosphere-Land system model, spectral version 2: FGOALS-s2. Adv Atmos Sci 30:561-576

Barlow M, Hoell A, Colby F (2007) Examining the wintertime response to tropical convection over the eastern Indian Ocean by modifying atmospheric heating in a global atmospheric model. Geophys Res Lett 34:L19702 
Briegleb BP, Bitz CM, Hunke EC, Lipscomb WH, Holland MM, Schramm JL, Moritz RE (2004) Scientific description of the sea ice component in the community climate system model, version three. NCAR Tech. Note NCAR/TN-463 + STR, 70pp

Chen M, Xie P, Janowiak JE, Arkin PA (2002) Global land precipitation: A 50-yr monthly analysis based on gauge observations. J Hydrometeorol 3:249-266

Chou C, Neelin JD (2004) Mechanisms of global warming impacts on regional tropical precipitation. J Clim 17:2688-2701

Collier JC, Zhang GJ (2009) Aerosol direct forcing of the summer Indian monsoon as simulated by the NCAR CAM3. Clim Dyn 32:313-332

Collins WD et al (2006) The community climate system model version 3 (CCSM3). J Clim 19:2122-2143

Dai FS, Yu RC, Zhang XH, Yu YQ (2004) A statistical low-level cloud scheme and its tentative application in a general circulation model. Acta Meteorol Sin 62(4):385-394 (in Chinese)

Ding YH, Wang Z, Sun Y (2007a) Inter-decadal variation of the summer precipitation in East China and its association with decreasing Asian summer monsoon. Part I: Observed evidences. Int J Climatol 28:1139-1161

Ding et al (2007b) Detection, causes and projection of climate change over China: an overview of recent progress. Adv Atmos Sci 6:954-971

Duan AM, Wu GX (2005) Role of the Tibetan Plateau thermal forcing in the summer climate patterns over subtropical Asia. Clim Dyn 24:793-807

Edwards JM, Slingo A (1996) A studies with a flexible new radiation code. I: choosing a configuration for a large-scale model. Q J R Meteorol Soc 122:689-720

Gill AE (1980) Some simple solutions for heat-induced tropical circulation. Q J R Meteorol Soc 106:447-462

Hansen JR, Ruedy R, Sato M, Lo K (2010) Global surface temperature change. Rev Geophys 48:RG4004

$\mathrm{He} B$ et al (2013) Influences of external forcing changes on the summer cooling trend over East Asia. Clim Change 117(4):829-841

Held IM, Soden BJ (2006) Robust responses of the hydrological cycle to global warming. J Clim 19:5686-5699

Hoerling M, Kuma A (2003) The perfect ocean for drought. Science 299:691-694

Holtslag AAM, Boville BA (1993) Local versus nonlocal boundarylayer diffusion in a global climate model. J Clim 6:1825-1842

Hurrell JW et al (2013) The community earth system model: a framework for collaborative research. Bull Am Meteorol Soc 94(9):1339-1360

IPCC (2013) Climate change 2013: the physical science basis. In: Stocker TF, Qin D, Plattner G-K, Tignor M, Allen SK, Boschung J, Nauels A, Xia Y, Bex V, Midgley PM (eds) Contribution of working group I to the fifth assessment report of the intergovernmental panel on climate change. Cambridge University Press, Cambridge, pp 3-32

Kalnay et al (1996) The NCEP/NCAR 40-year reanalysis project. Bull Am Meteorol Soc 77:437-470

Kiehl JT, Hack JJ, Bonan GB, Boville BA, Briegleb BP, Williamson DL, Rasch PJ (1996) Description of the NCAR community climate model (CCM3). NCAR Technical Note NCAR/ TN-420 + STR. doi:10.5065/D6FF3Q99

Lau WKM, Kim KM (2010) Fingerprinting the impacts of aerosols on long-term trends of the Indian summer monsoon regional rainfall. Geophys Res Letts 37:L16705

Liu YM, Wu GX, Liu H, Liu P (2001) Condensation heating of the Asian summer monsoon and the subtropical anticyclones in the Eastern Hemisphere. Clim Dyn 17:327-338

Liu YM, Wu GX, Hong JL, Dong BW, Duan AM, Bao Q, Zhou LJ (2012) Revisiting Asian monsoon formation and change associated with Tibetan Plateau forcing: II Change. Clim Dyn 39(5):1183-1195
Liu HL, Lin PF, Yu YQ, Zhang XH (2013) The baseline evaluation of LASG/IAP climate system ocean model (LICOM) version 2. Acta Meteorol Sin 26(3):318-329

Matsuno T (1966) Quasi-geostrophic motions in the equatorial area. J Meteorol Soc Jpn Ser II 44:25-43

Morice CP, Kennedy JJ, Rayner NA, Jones PD (2012) Quantifying uncertainties in global and regional temperature change using an ensemble of observation estimates: the HadCRUT4 dataset. J Geophys Res Atmos 117:22

Oleson KW et al (2004) Technical description of the community land model (CLM). NCAR/TN-461 + STR

Rayner NA et al (2003) Global analyses of sea surface temperature, sea ice, and night marine air temperature since the late nineteenth century. J Geophys Res Atmos 108:4407

Rodwell MR, Hoskins BJ (2001) Subtropical anticyclones and summer monsoon. J Clim 14:3192-3211

Slingo JM (1987) The development and verification of a cloud prediction scheme for the ECMWF model. Q J R Meteorol Soc 113:899-927

Smith TM, Arkin PA, Ren L, Shen SSP (2012) Improved reconstruction of global precipitation since 1900. J Atmos Ocean Technol 29:1505-1517

Sun ZA, Rikus L (1999) Parameterization of effective radius of cirrus clouds and its verification against observations. Q J R Meteorol Soc 125:3037-3056

Tiedtke M (1989) A comprehensive mass flux scheme for cumulus parameterization in large-scale models. Mon Wea Rev 117:1779-1800

Uppala SM et al (2005) The ERA-40 reanalysis. Q J Roy Meteor Soc 131(612):2961-3012

Vose RS et al (2012) NOAA's merged land-ocean surface temperature analysis. Bull Am Meteorol Soc 93:1677-1685

Wang B, Ding QH (2006) Changes in global monsoon precipitation over the past 56 years. Geophys Res Lett 33:L06711

Wang C, Kim D, Ekman AML, Barth MC, Rasch PJ (2009) Impact of anthropogenic aerosols on Indian summer monsoon. Geophys Res Lett 36:L21704

Webster PJ (1972) Response of the tropical atmosphere to local, steady forcing. Mon Weather Rev 100:518-541

Woodruff SD et al (2011) ICOADS Release 2.5: extensions and enhancements to the surface marine meteorological archive. Int J Climatol 31:951-967

Wu GX, Liu YM (2003) Summertime quadruplet heating pattern in the subtropics and the associated atmospheric circulation. Geophys Res Lett 30(5):1201. doi:10.1029/2002GL016209

Wu GX, Liu H, Zhao YC (1996) A nine-layer atmospheric general circulation model and its performance. Adv Atmos Sci 13:1-18

Wu GX, Liu YM, He B, Bao Q, Duan AM, Jin FF (2012) Thermal controls on the Asian summer monsoon. Sci Rep 2:404. doi:10.1038/srep00404

Wu GX, He B, Liu YM, Bao Q (2015) Location and variation of the summertime upper-troposphere temperature maximum over South Asia. Clim Dyn. doi:10.1007/s00382-015-2506-4

Yanai M, Esbensen S, Chu JH (1973) Determination of bulk properties of tropical cloud clusters from large-scale heat and moisture budgets. J Atmos Sci 30:611-627

Yang S, Webster PJ (1990) The effect of summer tropical heating on the location and intensity of the extratropical westerly jet streams. J Geophys Res Atmos 95:18705-18721

Zhang L, Zhou TJ (2011) An assessment of monsoon precipitation changes during 1901-2001. Clim Dyn 37:279-296

Zhou TJ, Gong DJ, Li J, Li B (2009) Detecting and understanding the multi-decadal variability of the East Asian Summer Monsoonrecent progress and state of affairs. Meteorol Z 18(4):455-467 